\section{Research can help build trust between MPA managers and community members}

In a study of residents living adjacent to the Ningaloo Marine Park in Western Australia, researchers found that scientific research conducted in the park had helped to build trust with regard to management of the MPA. The study also found that trust could be further enhanced through a targeted science communication and engagement strategy that targets different 'personality types' throughout the region.

The Ningaloo Research Program had been conducting research from 2006-16 on the Ningaloo Marine Park, home to Australia's largest fringing coral reef. Nearby the park are two towns, Exmouth and Coral Bay, which rely heavily on tourism to the reef. The park was nominated to be a World Heritage site, and during this process it was determined that there was a lack of trust between managers and local community members "resulting from perceived political and social concerns, and claims of misinformation and unfairness." The authors, therefore, conducted a case study on the Ningaloo Research Program to examine the extent at which the Ningaloo Research Program has helped to build trust since then.

137 members across the two communities were surveyed on a variety of topics, including their perceptions about the management of the marine park and the importance of science for making management decisions; and whether the scientific research undertaken in the region had increased trust collective action, social cohesion or communication among community members and MPA managers.

The study showed that the vast majority of community members felt they understood the rules of the marine park and supported these rules. They also believed they had fair access. The participants also trusted managers to make good decisions because of the scientific studies happening in the park. Furthermore, participants believed that perceived increases in trust have led to better social and environmental outcomes.

However, a small group of participants did not feel actively engaged in the park's management and would like to have more input. Information sharing between managers and community members did not seem to improve as a result of the Research Program with this specific group of community members.

The authors concluded that there are three typologies of residents in the region. The largest typology was of engaged optimists who value scientific input, trusted managers, and felt they were engaged in decision-making. The smallest group, disengaged pessimists, did not trust managers nor feel engaged in the management process. In between were the disengaged optimists, who value science and are trustful of management, but feel disengaged from managers. Demographics did not separate these groups, rather, it appears that the value placed in science is what made the two optimist typographies more trusting of managers.

Producing more science will not make a group which does not value science more trustful of managers. Other methods, like behavioral "nudges" that target subtle, subconscious behaviors might help increase participation in the consultation process and compliance with management decisions. Future communications efforts between managers and disengaged pessimists should focus on shared values to help build trust.
This is a summary of: Building trust among marine protected area managers and community members through scientific research: Insights from the Ningaloo Marine Park, Australia

Accessible at: https://marxiv.org/uarve

Authors: Chris Cvitanovic, Ingrid van Putten, Alistair Hobday, Rachel Kelly, Mary Mackay, Jan McDonald, Kelly Waples, Peter Barnes

Added to MarXiv: May 2018

Published: Marine Policy, 2018

Suggested Citation: Research can help build trust between MPA managers and community members. OCTO (2018). DOI: $10.17605 / O S F . I O /$ JRZ4Q

See more MarXiv summaries at https://www.marxivinfo.org/ summaries

Join the MarXiv Summaries monthly newsletter at https:// oct.to/marxivsum

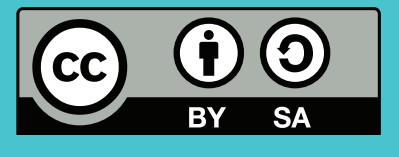

MarXiv is an ОстO Initiative

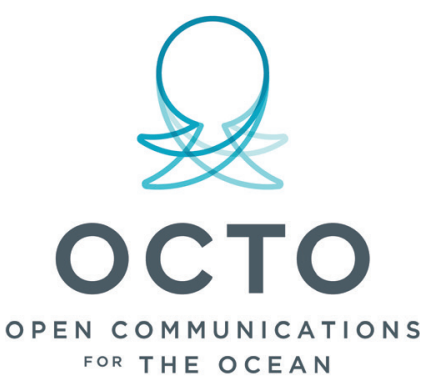

